\title{
Linkages Over Time Between Adolescents' Relationships with Parents and Friends
}

\author{
Irene H. A. De Goede $\cdot$ Susan J. T. Branje • \\ Marc J. M. H. Delsing · Wim H. J. Meeus
}

Received: 13 January 2009/ Accepted: 26 February 2009/Published online: 11 March 2009

(c) The Author(s) 2009. This article is published with open access at Springerlink.com

\begin{abstract}
This 5-wave longitudinal study examines linkages over time between adolescents' perceptions of relationships with parents and friends with respect to support, negative interaction, and power. A total of 575 early adolescents (54.1\% boys) and 337 middle adolescents (43.3\% boys) participated. Path analyses mainly showed bidirectional associations between adolescents' perceptions of parent-adolescent relationships and friendships with a predominantly stronger influence from parent-adolescent relationships to friendships than vice versa in early to middle adolescence and an equal mutual influence in middle to late adolescence. The findings support the theoretical ideas that perceptions of relationships with parents generalize to perceptions of relationships with friends and that relationship skills and principles of adolescent friendships generalize to relationships with parents. Furthermore, the results indicate that the influence of parents decreases, whereas the influence of friends increases, and that both social worlds become equally important and overlapping towards late adolescence.
\end{abstract}

I. H. A. De Goede $(\varangle)$ · S. J. T. Branje · W. H. J. Meeus Research Centre Adolescent Development, Utrecht University, P.O. Box 80140, 3508 TC Utrecht, The Netherlands

e-mail: I.H.A.deGoede@uu.nl

S. J. T. Branje

e-mail: S.Branje@uu.nl

W. H. J. Meeus

e-mail: W.Meeus@uu.nl

M. J. M. H. Delsing

Praktikon/ACSW, Radboud University Nijmegen,

Nijmegen, The Netherlands

e-mail: m.delsing@acsw.ru.nl
Keywords Adolescence - Parent-adolescent relationships · Friendships · Longitudinal analyses . Linkages

Due to psychosocial and cognitive development, relationships with parents and friends are considerably different in adolescence compared to childhood (Collins and Repinski 1994) and continue to change throughout the teenage years (Furman and Buhrmester 1992). Parent-adolescent relationships gradually become more equal (De Goede et al. 2009; Russell et al. 1998; Youniss and Smollar 1985) and less conflictual (De Goede et al. 2009; Furman and Buhrmester 1992) as adolescents become increasingly autonomous and individuated from their parents (Blos 1979; Grotevant and Cooper 1986) and spend less time with parents (Larson et al. 1996). In the meantime, adolescent friendships become increasingly close and supportive (De Goede et al. 2009; Furman and Buhrmester 1992; Helsen et al. 2000; Rubin et al. 2006; Shulman et al. 1997) and adolescents spend more and more time with their peers (Larson et al. 1996). Thus, the focus of adolescents gradually shifts from the family to peers (Brown, 2004; Laursen and Bukowski 1997). Several theories assume that the development of parent-adolescent relationships and friendships is associated (e.g., organizational system perspective, Laursen and Bukowski 1997; attachment theory, Schneider et al. 2001). In this study, we investigate whether parent-adolescent relationships and friendships are related and whether these relationships predict each other over time.

Different theoretical perspectives suggest a link between relationships with parents and relationships with peers. Firstly, attachment theory assumes that adolescents have formed mental representations based on experiences in the 
relationships with their parents and that they will use these relationship models to understand and construct their relationships with friends (Bowlby 1969; Furman et al. 2002). Secondly, according to social learning theory (Bandura 1977), adolescents' relationships with parents might affect other social relationships like friendships through a process of modeling and imitation. Thirdly, the social interactional perspective (Burks and Parke 1996; Parke and Buriel 2006) suggests that children learn cognitive representations of social relationships through their relationships with parents. Parental cognitive representations are found to be linked to adolescents' cognitive representations and adolescents' social competence (McDowell et al. 2002). In this way, cognitive models are supposed to generalize from parent-adolescent relationships to adolescent friendships (Parke and Buriel 2006). Finally, family systems theory suggests that families are hierarchically arranged and that adolescent behavior is therefore influenced by parents' behavior (Erel and Burman 1995). Furthermore, it is proposed that parent-child interaction is one way in which parents can influence peer competence (Parke et al. 1994). In sum, different perspectives predict that relationships with parents might influence relationships with friends.

In contrast, an effect from adolescent friendships to parent-adolescent relationships could be expected based on differences between parent-adolescent relationships and friendships. For adolescents, parent-child relationships are involuntary, hierarchical, and constrained by kinship, whereas friendships are voluntary, symmetrical, and more easily dissolved (Hartup 1989; Laursen 1996; Laursen and Bukowski 1997; Laursen and Collins 1994; Youniss and Smollar 1985). Consequently, different relationship principles are involved. In friendships, adolescents learn to interact with each other on an equal basis, which is the interaction style that they will predominantly use and need in their future adult life (Graziano 1984; Laursen and Bukowski 1997). The horizontal nature of friendships is particularly suited to learn and practice this egalitarian and symmetrical style, and will become better understood in friendships during the adolescent years. This gives rise to the prediction that the relationship skills learned in friendships are later generalized to other relationships like parent-adolescent relationships, and thus an effect from adolescent friendships to parent-adolescent relationships is expected.

It is probable that the linkages between parent-adolescent relationships and adolescent friendships change over time due to adolescent development. Since parent-adolescent relationships become more equitable over time (McGue et al. 2005; Russell et al. 1998) and adolescents become increasingly autonomous (Blos 1979; Grotevant and Cooper 1986), it might be argued that the influence of parent-adolescent relationships on adolescent friendships diminishes as adolescents grow older. Because closeness and interdependence in friendships increase (Selman 1981; Shulman et al. 1997), adolescent friendships are likely to become more salient and influencing over time. It is therefore to be expected that the influence of friendships on parent-adolescent relationships increases with age.

The focus of this study lies on the perception of adolescents regarding support, negative interaction, and power, which are key dimensions in many theories on close relationships. Although different researchers have distinguished various aspects of relationship quality, (Berndt 2002; Bukowski et al. 1994; Furman and Buhrmester 1985; Furman 1996; Parker and Asher 1993), all distinctions include aspects of closeness, intimacy, and support on the one hand, and negative interaction or conflict on the other hand. For example, attachment theory emphasizes support from parents as a secure basis to form new relationships (Collins and Laursen 2004) and assumes that a need for support stimulates friendships (Bowlby 1969; Rubin et al. 2006). In addition, psychoanalytic theory and Sullivan's developmental model of interpersonal relationships emphasize that friends become increasingly important as providers of support, whereas parents become relatively less important sources of support (Blos 1967; Rubin et al. 2006; Sullivan 1953). The role of negative interaction is stressed by the social relational perspective, which states that negative interaction is fundamental in close relationships, resulting from the need to integrate different objectives and expectations (Laursen and Collins 1994). In addition, several theories emphasize that equality and interdependence are important characteristics of close relationships. Sullivan's developmental model of interpersonal relationships hypothesizes that egalitarian relationships stimulate adolescent well-being and self-validation (Rubin et al. 2006; Sullivan 1953). Similarly, interdependence models and the social relational perspective highlight the balance of power, with mutual influences, reciprocity, and perception of equality as the main characteristic of close relationships (Collins and Laursen 2004; Laursen 1996).

Because of the importance of support, negative interaction, and power in theories of adolescent development, we chose to address these three different dimensions in our study. Due to the large variety of concepts in this field, we will describe both empirical research about support, negative interaction, and power in parent-adolescent relationships and adolescent friendships, as well as empirical research about related relationship dimensions.

For support and related relationship dimensions, positive correlations have been found between relationships with parents and friends. Studies showed concurrent positive correlations between parental attachment and peer attachment (Wilkinson 2006), between parental support and 
friendship quality (Zimmermann 2004), between parental attachment and friendship quality (Benson et al. 2006; Zimmermann 2004), between family connectedness and peer connectedness (Bell et al. 1988), and between parental support and friendship or peer support (Cui et al. 2002; Furman et al. 2002; Helsen et al. 2000; Stice et al. 2004; Young et al. 2005). In addition, a meta-analysis showed a significant over-time correlation between early child-parent attachment and friendships later on in childhood and adolescence (Schneider et al. 2001). Furthermore, a longitudinal study using latent growth curves also showed a positive correlation between the slope of parental support and the slope of peer support (Stice et al. 2004), indicating that changes in parental support and peer support are related. All in all, these findings indicate that a higher level of support from parents is related to a higher level of support from friends.

Positive correlations have also been found concurrently for dimensions related to negative interaction and power. For example, affective intensity of conflict with parents and affective intensity of conflict with friends (Collins et al. 1997), parental hostile behavior and friendship hostile behavior (Cui et al. 2002), and negative interaction with parents and negative interaction with friends (Furman et al. 2002) were found to be positively related. Furthermore, a positive correlation was found concurrently between the distribution of power in parent-adolescent relationships and adolescent friendships (Laursen et al. 2000). Generally speaking, these studies suggest that higher levels of negative interaction with parents are related to higher levels of negative interaction with friends. Also, power distributions are supposed to be relatively similar in adolescent relationships with parents and friends.

In sum, different theories provide contrasting suggestions about the presence and the direction of possible linkages over time between parent-adolescent relationships and adolescent friendships. Although several studies showed concurrent linkages between adolescent relationships with parents and friends, longitudinal research is necessary to investigate how these relationship developments affect each other over time. In this study, we will therefore longitudinally investigate linkages between parent-adolescent relationships and adolescent friendships.

\section{Aim of the Present Study}

We will simultaneously test expectations based on two contrasting perspectives on possible linkages over time between parent-adolescent relationships and adolescent friendships.

Based on several theoretical perspectives, we expect that relationship quality of parent-adolescent relationships influences relationship quality of adolescents' relationships with best friends over time. Based on contrasting ideas, we expect a generalization principle in which perceived relationship quality of adolescent friendships predicts perceived relationship quality of parent-adolescent relationships over time. We will refer to these perspectives as the parent effect model and the friend effect model, respectively.

Furthermore, we will investigate whether age effects occur with respect to associations between adolescents' perceptions of relationships with parents and adolescents' perceptions of friendships. We expect that the possible influence of parent-adolescent relationships on adolescent friendships diminishes as adolescents grow older, whereas adolescent friendships become more influencing on parentadolescent relationships over time.

\section{Method}

Participants

Data for this study were collected as part of an ongoing longitudinal research project on conflict and management of relationships (CONAMORE; Meeus et al. 2004). The current study uses five measurement waves with a 1-year interval between each of the waves for all participants. From 2001 onwards, data collection took place in the fall of each year. The longitudinal sample consists of 1,313 participants. To prevent interdependence in the data, two criteria were used to select adolescents from the total sample. Firstly, when two or more target adolescents selected the same person as their best friend in a particular wave, one of these dyads was randomly selected. Secondly, when two adolescents selected each other as their best friend in a particular wave and thus formed a mutual friendship, one of the two adolescents was randomly selected to avoid interdependence in the data. This selection was conducted for every measurement wave separately and resulted in a sample of 912 unique and fully independent friendship perceptions, since each friendship in the final sample was reported on only once. The final sample included 457 boys (50.1\%) and 455 girls (49.9\%). Two age groups were represented: 575 early to middle adolescents $(63.0 \%)$, who were on average 12.4 years of age $(\mathrm{SD}=.60)$ and 337 middle to late adolescents $(37.0 \%)$, who were on average 16.7 years of age $(\mathrm{SD}=.82)$ during the first wave of assessment. The early to middle adolescent group consisted of 311 boys $(54.1 \%)$ and 264 girls $(45.9 \%)$. The middle to late adolescent group consisted of 146 boys ( $43.3 \%)$ and 191 girls (56.7\%). Because both age groups were assessed during five measurement waves, a total age range from 12 to 16 and from 16 to 20 years was 
available. Most participants were Dutch $(84.5 \%)$, and others identified themselves as part of a Dutch non-western ethnic minority group. Most participants lived with both parents $(84.0 \%)$. The participants were in junior high and high schools at Time 1 . The early and middle adolescent groups were comparable regarding ethnic group $\left(\chi^{2}(4\right.$, $N=879)=5.6, p=.23)$ and living situation with parents $\left(\chi^{2}(6, N=886)=9.6, p=.15\right)$. However, there were differences regarding sex, with more boys in the early adolescent group and more girls in the middle adolescent group $\left(\chi^{2}(1, \quad N=912)=9.8, \quad p=<.01\right)$. Only 110 $(12.1 \%)$ of the participants reported on the same friendship across the five measurement waves.

There was no sample attrition from Wave 1 to Wave 2. Sample attrition was 3.95\% from Wave 2 to Wave 3, .57\% from Wave 3 to Wave 4, and $1.26 \%$ from Wave 4 to Wave 5. Models were estimated in Mplus with a Robust Maximum Likelihood estimation method (Satorra and Bentler 1994), to provide better estimations of standard errors when normality assumptions are violated.

\section{Procedure}

The participating adolescents were recruited from various high schools in the province of Utrecht, the Netherlands. Participants received an invitation letter, describing the research project and goals and explaining the possibility to decline from participation. Both parents and adolescents provided informed consent. More than $99 \%$ of the approached high school students decided to participate. The participants completed the questionnaires at their own high school or at home, during annual assessments. Confidentiality of responses was guaranteed. Verbal and written instructions were offered. The adolescents received $€ 10$ as a reward for every wave they participated in. Participants answered the questionnaires about their relationship with their mother, their father, and their best friend separately. For the questionnaire on friendship quality, participants were asked to identify their best friend and answer the items while thinking about the relationship with this best friend. It was not possible to select a romantic partner as their best friend. Participants were not restricted to select a same-age, same-school, or same-gender friend.

\section{Measures}

\section{Support}

The support scale measures the amount of support from mothers, fathers, and best friends separately as perceived by adolescents. Support was assessed using the short version of the Network of Relationships Inventory (Furman and Buhrmester 1985, 1992). The support scale consists of twelve items, including items from different subscales like companionship, instrumental aid, intimacy, nurturance, affection, admiration, and reliable alliance. Answers were indicated on a 5-point Likert scale (ranging from $1=a$ little or not at all to $5=$ more is not possible). Examples of items are: "Does your mother like or approve of the things you do?" and "How much does your best friend really care about you?"

\section{Negative Interaction}

The negative interaction scale assesses the intensity of negative interaction in adolescent relationships according to the perceptions of adolescents for relationships with their mothers, fathers, and best friends separately. Negative interaction was assessed by combining the conflict and antagonism subscales of the Network of Relationships Inventory (Furman and Buhrmester 1985, 1992), which is the original short form to assess negative interaction. The negative interaction scale consists of six items. The participants indicated their answers on a 5-point Likert scale (ranging from $1=$ a little or not at all to $5=$ more is not possible). Examples of items are: "Do you and your father get on each other's nerves?" and "How much do you and your best friend get upset with or mad at each other?"

\section{Power}

The power scale measures the amount of power the adolescents attributed to their parents and friends, for relationships with their mothers, fathers, and best friends separately. Power was assessed by combining the relative power and the dominance subscales of the Network of Relationships Inventory (Furman and Buhrmester 1985, 1992). Since the power items and dominance items are formulated in the same way, they all measure the adolescents' perception about the extent in which the other person in the relationship is relatively powerful in the relationship. In this way, the items contrast dominance of the partner with either equality or dominance of the reporter. The power scale consists of six items. Answers were given based on a 5-point Likert scale (ranging from $1=$ a little or not at all to $5=$ more is not possible). Low scores on the power scale show that adolescents do not see the person they are reporting about as more powerful, leaving open the possibility that the adolescent is more powerful than the other person as well as the possibility that the relationship is more egalitarian. High scores indicate that adolescents perceive the person they are reporting about as more powerful and feel their relationship is less equal. Examples of items are: "How often does your mother tell you what to do?" and "To what extent is your best friend the boss in your relationship?" 
Table 1 Overview of minimum factor loadings and alpha ranges for all variables

\begin{tabular}{lllll}
\hline & \multicolumn{3}{l}{ Factor loadings } & \multirow{2}{*}{ Alpha range } \\
\cline { 2 - 3 } & 1 & 2 & 3 & \\
\hline Mother & & & & \\
$\quad$ Support & $>.48$ & $<.19$ & $<.11$ & $.88-.91$ \\
$\quad$ Negative interaction & $<.06$ & $>.70$ & $<.06$ & $.87-.92$ \\
$\quad$ Power & $<.03$ & $<.18$ & $>.56$ & $.82-.88$ \\
Father & & & & \\
$\quad$ Support & $>.41$ & $<.16$ & $<.15$ & $.91-.92$ \\
$\quad$ Negative interaction & $<.06$ & $>.69$ & $<.11$ & $.89-.92$ \\
$\quad$ Power & $<.13$ & $<.16$ & $>.60$ & $.87-.91$ \\
Friend & & & & \\
$\quad$ Support & $>.47$ & $<.12$ & $<.22$ & $.92-.93$ \\
$\quad$ Negative interaction & $<.05$ & $>.57$ & $<.07$ & $.82-.87$ \\
$\quad$ Power & $<.23$ & $<.05$ & $>.45$ & $.82-.86$ \\
\hline
\end{tabular}

\section{Reliability and Validity of the NRI}

Three different explorative factor analyses were conducted on the NRI items, one for relationships with mothers, one for relationships with fathers, and one for relationships with friends (see Table 1). The results showed factor loadings above .40 for three factors and no cross-loadings higher than .22. Internal consistencies were high for all variables (see Table 1). The factor and construct validity of the NRI are adequate (Edens et al. 1999).

\section{Results}

\section{Plan of Analysis}

To examine the cross-effects between adolescents' perceptions of the quality of their relationships with parents and friends over time, we conducted path analyses with crosslagged effects by means of structural equation modeling. We tested the path models for each relationship dimension (support, negative interaction, and power) separately, using a 2-group design to investigate differences between the two age groups. Within each model, the two observed scale scores for relationships with mothers and relationships with fathers together formed a latent variable representing adolescents' relationships with parents. We established factorial invariance by fixing the factor loadings of the scale scores of relationships with fathers on the latent variable to be equal across waves. The factor loadings of the scale scores of relationships with mothers on the latent variable were constrained to 1 to scale the factor. In each model, friendships were represented by an observed variable, which is the scale score on the appropriate relationship dimension.
Model comparisons within each relationship dimension separately showed that higher order autoregressive paths were needed for each age group in both parent-adolescent relationships and adolescent friendships and these paths were therefore included in the model. We allowed errors for corresponding scores on relationships with mothers and fathers separately to correlate over the measurement waves, in order to reduce reporter bias. This was not necessary with respect to the errors for the scores on friendships.

Within each age group, for the sake of parsimony, we tested whether it was possible to fix the stability paths between adjacent waves, the concurrent correlations indicating correlated change (Wave 2 to Wave 5), and the crosslagged paths from parents to friends (Wave 1 parents to Wave 2 friends equals Wave 2 parents to Wave 3 friends etcetera), from friends to parents (Wave 1 friends to Wave 2 parents equals Wave 2 parents to Wave 3 friends etcetera). We also tested whether it was possible to fix all cross-lagged paths in both directions to be equal. Using chi-square difference tests, we determined which parameter constraints could be made without significantly impairing the model fit (Kline 2005). The models were adjusted accordingly. Table 2 lists the parameters that could be constrained within cohorts without significantly reducing the model fit (see columns 1 and 2 for each relationship dimension).

Next, to examine cohort effects, we tested whether it was possible to fix the different paths to be equal across the two age groups within each relationship dimension. We stepwise tested whether it was possible to fix the variances and correlation at the first measurement wave, the stability paths between adjacent waves, the concurrent correlations indicating correlated change (Wave 2 to Wave 5), and the crosslagged paths from parents to friends (Wave 1 parents to Wave 2 friends equals Wave 2 parents to Wave 3 friends etcetera), from friends to parents (Wave 1 friends to Wave 2 parents equals Wave 2 parents to Wave 3 friends etcetera), and all cross-lagged paths in both directions, to be equal across the two age groups. Again using chi-square difference tests, we determined which parameter constraints could be made without significantly impairing the model fit and the models were adjusted accordingly. Table 2 lists the parameters that could be constrained without significantly reducing the model fit. Table 3 shows the model comparison tests and the model fit indices of different models. Results and fit indices of the best fitting models of these series of analyses are displayed in Figs. 1-6.

\section{Over-Time Linkages Between Perceived Support from Parents and Friends}

In both age cohorts, we found that adolescents' perceptions of support from parents and friends were positively associated at Time 1. Furthermore, support from parents 
Table 2 Overview of parameters that could be constrained without significantly reducing the model fit

\begin{tabular}{|c|c|c|c|c|c|c|c|c|c|}
\hline \multirow[t]{3}{*}{ Parameters } & \multicolumn{9}{|c|}{ Constraints } \\
\hline & \multicolumn{3}{|l|}{ Support } & \multicolumn{3}{|c|}{ Negative interaction } & \multicolumn{3}{|l|}{ Power } \\
\hline & Cohort 1 & Cohort 2 & $\begin{array}{l}\text { Across } \\
\text { cohorts }\end{array}$ & Cohort 1 & Cohort 2 & $\begin{array}{l}\text { Across } \\
\text { cohorts }\end{array}$ & Cohort 1 & Cohort 2 & $\begin{array}{l}\text { Across } \\
\text { cohorts }\end{array}$ \\
\hline Initial correlation (T1) & & & $\mathrm{x}$ & & & $\mathrm{x}$ & & & $\mathrm{x}$ \\
\hline \multicolumn{10}{|c|}{ Stability paths (adjacent waves) } \\
\hline Parents & $\mathrm{x}$ & $\mathrm{x}$ & $\mathrm{x}$ & $\mathrm{x}$ & $\mathrm{x}$ & $\mathrm{x}$ & $\mathrm{x}$ & $\mathrm{x}$ & $\mathrm{x}$ \\
\hline Friends & $\mathrm{x}$ & & & $\mathrm{x}$ & $\mathrm{x}$ & $\mathrm{x}$ & $\mathrm{x}$ & $\mathrm{x}$ & \\
\hline Correlated change (T2-T5) & $\mathrm{x}$ & $\mathrm{x}$ & $\mathrm{x}$ & $\mathrm{x}$ & $\mathrm{x}$ & $\mathrm{x}$ & $\mathrm{x}$ & $\mathrm{x}$ & $\mathrm{x}$ \\
\hline \multicolumn{10}{|l|}{ Initial variances } \\
\hline Parents & & & $\mathrm{x}$ & & & & & & $\mathrm{x}$ \\
\hline Friends & & & & & & $\mathrm{x}$ & & & $\mathrm{x}$ \\
\hline \multicolumn{10}{|l|}{ Cross-lagged paths } \\
\hline Parents $\rightarrow$ friends & $\mathrm{x}$ & $\mathrm{x}$ & & $\mathrm{x}$ & $\mathrm{x}$ & $\mathrm{x}$ & $\mathrm{x}$ & $\mathrm{x}$ & $\mathrm{x}$ \\
\hline Friends $\rightarrow$ Parents & $\mathrm{x}$ & $\mathrm{x}$ & $\mathrm{x}$ & & $\mathrm{x}$ & & $\mathrm{x}$ & $\mathrm{x}$ & $\mathrm{x}$ \\
\hline$P \rightarrow f=f \rightarrow P$ & & $\mathrm{x}$ & & & $\mathrm{x}$ & & $\mathrm{x}$ & $\mathrm{x}$ & $\mathrm{x}$ \\
\hline
\end{tabular}

Note $: \mathrm{x} \rightarrow$ these paths were constrained to be similar, cohort $1=$ early to middle adolescence, cohort $2=$ middle to late adolescence

$P$ parents, $f$ friends, T2-T5 from Wave 2 to Wave 5

Table 3 Model fit indices and model comparison tests for support, negative interaction and power

\begin{tabular}{|c|c|c|c|c|c|c|c|c|c|c|}
\hline & \multicolumn{6}{|c|}{ Model fit indices } & \multicolumn{4}{|c|}{ Model comparison tests } \\
\hline & $\operatorname{MLr} \chi^{2}$ & $d f$ & $\mathrm{SCF}^{\mathrm{a}}$ & CFI & TLI & RMSEA & & SBdiff $^{b}$ & $\Delta d f$ & $p$ \\
\hline \multicolumn{11}{|l|}{ Support } \\
\hline $\begin{array}{l}\text { Start model: autoregression paths and } \\
\text { error correlations included }\end{array}$ & 105.987 & 98 & 1.224 & 0.998 & 0.996 & 0.013 & & & & \\
\hline $\begin{array}{l}\text { After stepwise fixation of stability, concurrent, } \\
\text { and cross-lagged paths within age groups }\end{array}$ & 128.718 & 125 & 1.297 & 0.999 & 0.999 & 0.008 & 1 vs. 2 & 14.553 & 27 & 0.975 \\
\hline $\begin{array}{l}\text { After stepwise fixation of mutual cross-lagged } \\
\text { paths }(P \rightarrow f=f \rightarrow P) \text { within age groups }\end{array}$ & 132.357 & 126 & 1.295 & 0.999 & 0.998 & 0.011 & 2 vs. 3 & 3.482 & 1 & 0.062 \\
\hline After stepwise fixation across two age groups & 143.491 & 131 & 1.309 & 0.997 & 0.996 & 0.014 & 3 vs. 4 & 6.700 & 5 & 0.244 \\
\hline \multicolumn{11}{|l|}{ Negative Interaction } \\
\hline $\begin{array}{l}\text { Start model: autoregression paths and error } \\
\text { correlations included }\end{array}$ & 98.117 & 98 & 1.171 & 1.000 & 1.000 & 0.002 & & & & \\
\hline $\begin{array}{l}\text { After stepwise fixation of stability, concurrent, } \\
\text { and cross-lagged paths within age groups }\end{array}$ & 122.263 & 125 & 1.271 & 1.000 & 1.002 & 0.000 & 1 vs. 2 & 14.778 & 27 & 0.972 \\
\hline $\begin{array}{l}\text { After stepwise fixation of mutual cross-lagged } \\
\text { paths }(P \rightarrow f=f \rightarrow P) \text { within age groups }\end{array}$ & 123.295 & 126 & 1.273 & 1.000 & 1.002 & 0.000 & 2 vs. 3 & 0.678 & 1 & 0.410 \\
\hline After stepwise fixation across two age groups & 134.954 & 132 & 1.302 & 0.999 & 0.998 & 0.007 & 3 vs. 4 & 6.101 & 6 & 0.412 \\
\hline \multicolumn{11}{|l|}{ Power } \\
\hline $\begin{array}{l}\text { Start model: autoregression paths and error } \\
\text { correlations included }\end{array}$ & 125.902 & 122 & 1.251 & 0.999 & 0.998 & 0.008 & & & & \\
\hline $\begin{array}{l}\text { After stepwise fixation of stability, concurrent, } \\
\text { and cross-lagged paths within age groups }\end{array}$ & 159.225 & 149 & 1.259 & 0.997 & 0.996 & 0.012 & 1 vs. 2 & 25.729 & 27 & 0.534 \\
\hline $\begin{array}{l}\text { After stepwise fixation of mutual cross-lagged } \\
\text { paths }(P \rightarrow f=f \rightarrow P) \text { within age groups }\end{array}$ & 171.312 & 153 & 1.262 & 0.995 & 0.994 & 0.016 & 2 vs. 3 & 8.799 & 4 & 0.066 \\
\hline After stepwise fixation across two age groups & 179.259 & 160 & 1.274 & 0.995 & 0.994 & 0.016 & 3 vs. 4 & 5.173 & 7 & 0.639 \\
\hline
\end{tabular}

Note: ${ }^{a}$ Scaling correction factor (Satorra and Bentler 2001)

b Adjusted $\Delta \chi^{2}$ according to Satorra-Bentler's (SB) scaling corrections (Satorra and Bentler 2001) 
Fig. 1 Linkages between support from parents and friends in early to middle adolescence. Note: $* p<.05, * * p<.01$

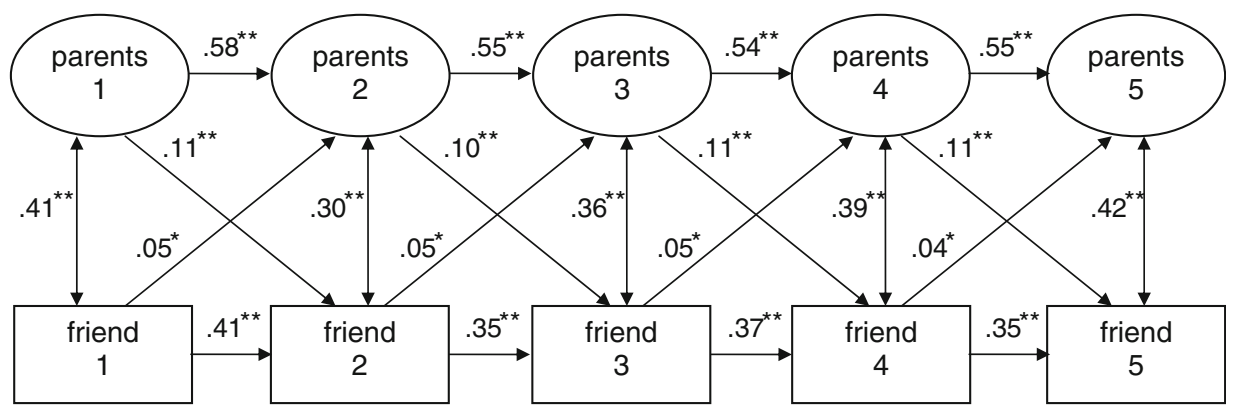

$\chi^{2}=143.5, \mathrm{df}=131, \mathrm{CFI}=1.00, \mathrm{RMSEA}=0.01$

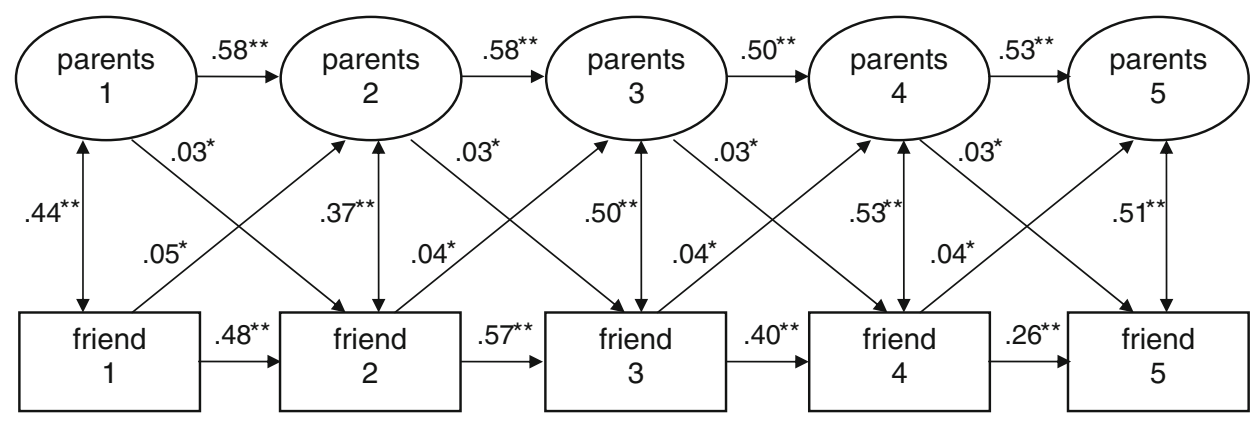

$\chi^{2}=143.5, \mathrm{df}=131, \mathrm{CFI}=1.00, \mathrm{RMSEA}=0.01$

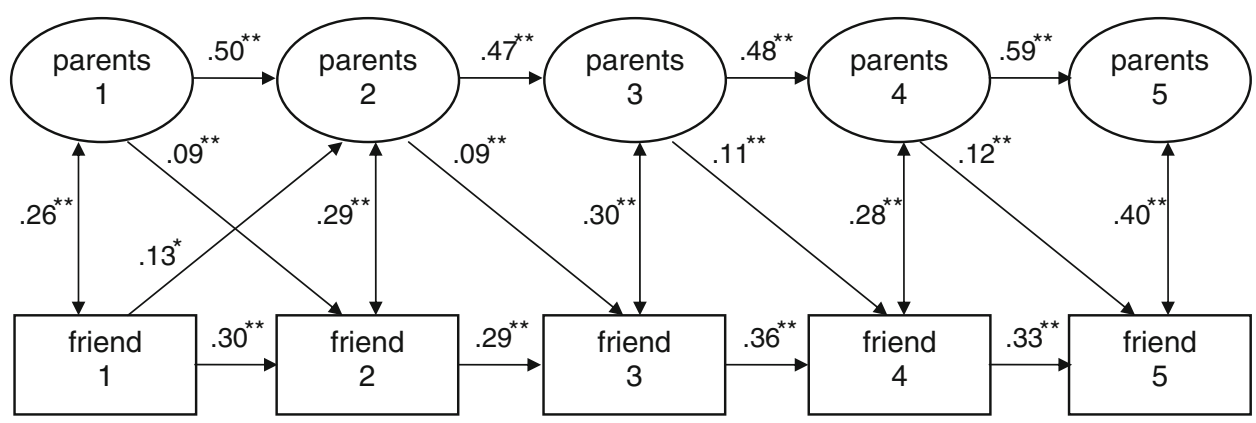

$\chi^{2}=134.95, \mathrm{df}=132, \mathrm{CFI}=1.00, \mathrm{RMSEA}=0.01$

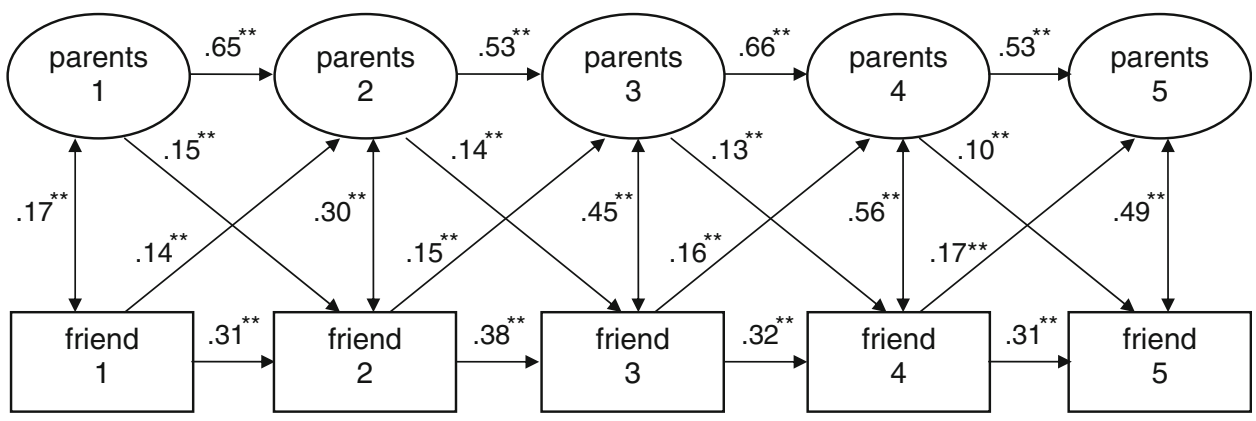

$\chi^{2}=134.95, \mathrm{df}=132, \mathrm{CFI}=1.00, \mathrm{RMSEA}=0.01$
Fig. 4 Linkages between negative interaction with parents and friends in middle to late adolescence

Note: $* p<.05, * * p<.01$
Fig. 3 Linkages between negative interaction with parents and friends in early to middle adolescence. Note: $* p<.05, * * p<.01$
Linkages between Note: $* p<.05, * * p<.01$ 
Fig. 5 Linkages between power of parents and friends in early to middle adolescence. Note: $* p<.05, * * p<.01$

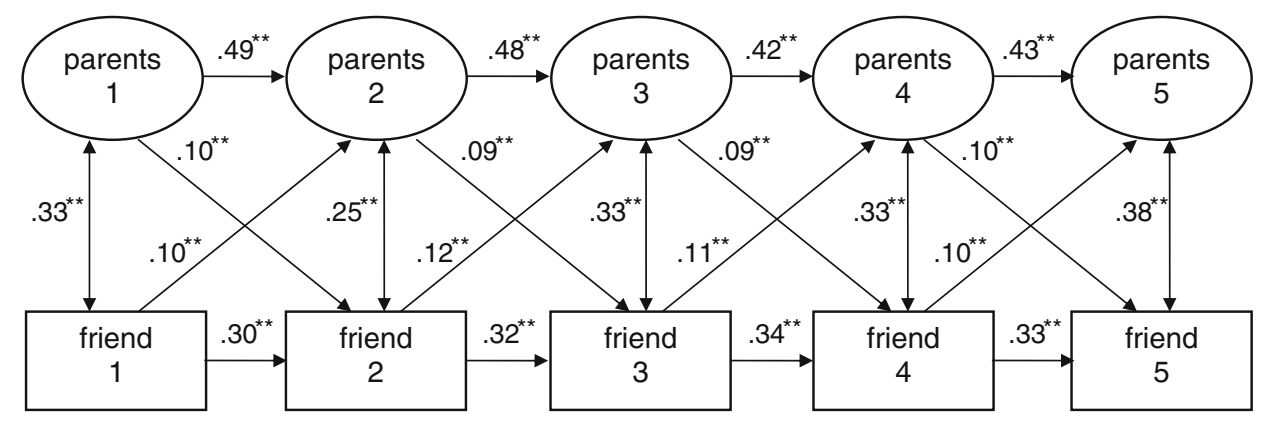

$\chi^{2}=179.259, \mathrm{df}=160, \mathrm{CFI}=1.00, \mathrm{RMSEA}=0.02$

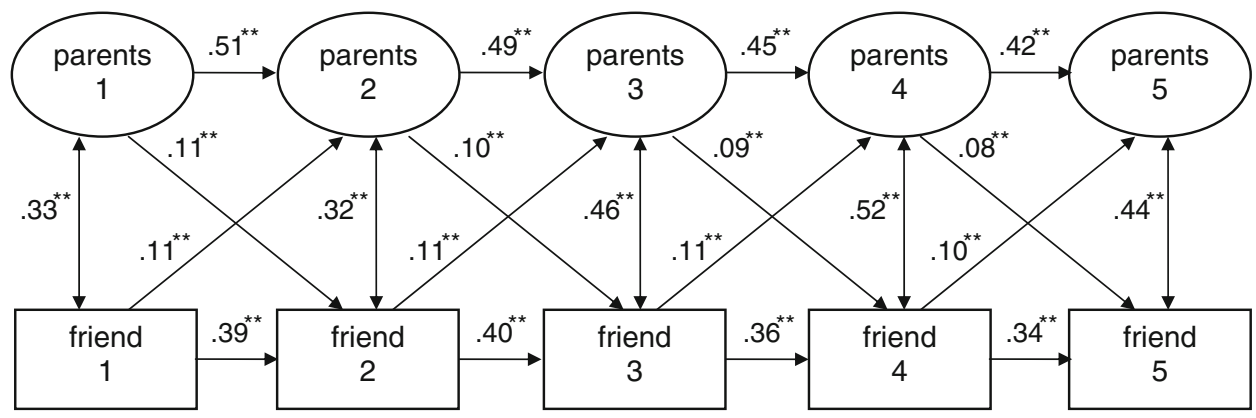

$\chi^{2}=179.259, \mathrm{df}=160, \mathrm{CFI}=1.00, \mathrm{RMSEA}=0.02$
Fig. 6 Linkages between power of parents and friends in middle to late adolescence. Note: $* p<.05, * * p<.01$ parent-adolescent negative interaction was only significant from the first to the second measurement wave, when adolescents were 12 and 13 years of age (see Fig. 3). The significant bidirectional effects between adolescents' perceptions of negative interaction with parents and friends in middle to late adolescence could be constrained within this cohort, indicating that these effects were of similar strength in both directions (see Fig. 4) and that the influence of parents and friends was equally strong. In sum, these findings show a consistent influence of negative interaction with parents to negative interaction with friends and a stronger influence from negative interaction with friends to negative interaction with parents in middle to late adolescence as compared to early to middle adolescence.

\section{Over-Time Linkages Between Power of Parents} and Friends

Adolescents' perceptions of power of parents and power of friends were positively associated at Time 1 . Furthermore, we found in both the early to middle adolescence group and the middle to late adolescence group that adolescents' perceptions of parental power predicted friends' power and vice versa. The cross-lagged effects from parents to friends and the effects from friends to parents could be constrained both within and across cohorts, indicating that these effects were of equal strength and were also similar across age cohorts (see Figs. 5, 6). So all in all, these findings show a consistent bidirectional influence of similar strength cohort, the effect of friends' negative interaction on 
between parental power and friends' power throughout adolescence (see Figs. 5, 6) showing both a parent effect and a friend effect.

\section{Discussion}

This study addressed linkages over time between adolescents' perceptions of relationship quality in relationships with parents and in relationships with friends. The relationship characteristics support, negative interaction, and power were assessed in a 5-wave longitudinal study of early to middle (ages 12-16) and middle to late adolescence (ages 16-20). These longitudinal data allowed us to test whether adolescents' perceptions of relationships with parents and friends are related and to establish the direction of effects between these types of relationships. In this study, we aimed to test expectations based on two contrasting perspectives: the parent effect model, which suggested an effect from parent-adolescent relationships to adolescent friendships, and the friend effect model, which proposed an effect from adolescent friendships to parentadolescent relationships. Overall, the results indicated a bidirectional association between parent-adolescent relationships and friendships with a stronger influence from parent-adolescent relationships to friendships than vice versa in early to middle adolescence and an equal mutual influence in middle to late adolescence. Thus, support for both the parent effect model and the friend effect model was found.

Our results systematically showed that perceptions of adolescents about their relationships with parents and friends were positively associated at the age of 12 as well as at the age of 16. Thus, when adolescents perceived their parents as more supportive, they also perceived their friends as more supportive. The same was true regarding negative interaction and power. These findings indicate an overlap between how interactions are experienced in different social worlds, that is, regarding closed relationships within the family and regarding open relationships within the peer group (Laursen and Bukowski 1997). These positive associations between adolescents' perceptions of relationships with parents and friends were also found longitudinally, indicating that adolescents' perceptions of relationships with parents and friends change in the same direction.

The consistent significant influence from relationships with parents to relationships with friends confirmed a parent effect model suggesting that perceptions of relationships with parents generalize to friendships (Schneider et al. 2001). In the same manner, a consistent significant influence from adolescents' perceptions of relationships with friends to relationships with parents (except regarding negative interaction from early to middle adolescence) supported the friend effect model, as based on based on the differences between parent-adolescent relationships and friendships (Laursen and Collins 1994). These latter findings suggest a generalization from relationship skills and principles of adolescent friendships to relationships with parents. Overall, the bidirectional associations indicate that parent-child relationships and friendships mutually influence each other during adolescence.

We found that the influence of parents decreased with age regarding support, whereas the influence of friends increased with age regarding negative interaction. For support and negative interaction in early to middle adolescence, the data supported the parent effect model more than the friend effect model, whereas both models were equally strong in middle to late adolescence. These findings confirm the notion that parents become less important in the lives of adolescents. Also consistent with the idea that parents become less important in the lives of adolescents were the diminishing effects across cohorts from parents to friends regarding support. Moreover, the increasing effects across cohorts from friends to parents regarding negative interaction confirm the idea that friends become more important in the lives of adolescents as they grow older (Brown 2004; Larson et al. 1996; Laursen and Bukowski 1997). This decreasing influence from parents and the increasing influence from friends might, however, be domain-specific since these effects were only found regarding support and negative interaction, respectively.

Finally, we found that the mutual influence between adolescents' perceptions of parent-adolescent relationships and adolescent friendships was of equal strength in middle to late adolescence, indicating that from middle adolescence onwards there is equal support for both the parent effect model and the friend effect model. These findings show that both social worlds become equally important and overlapping towards late adolescence.

Possible explanations for these results can be found in cognitive and psychosocial development. Due to improving socio-cognitive skills of adolescents, equal relationships become more salient during adolescence. Regarding parent-child relationships, adolescents become more independent from their parents and gain more autonomy (Blos 1979; Zimmer-Gembeck and Collins 2003). As a result, parent-adolescent relationships become more equally balanced with respect to power (De Goede et al. 2009; Furman and Buhrmester 1992) and parents start to have less influence on the lives of their adolescent child. Whereas the influence of parents diminishes, the influence of friends gains in importance. Adolescents become more able to take each others' perspectives into account (Selman 1980) and, as a result, friendships become more balanced and influencing. Since friendships form the first true type of 
egalitarian relationships, adolescents mainly practice relationship principles of equality in friendships, which is important for the formation and continuation of relationships in their future adult life (Graziano 1984; Laursen and Bukowski 1997). Thus, relationship skills learned in egalitarian and symmetrical friendships become more salient during the adolescent years and generalize to other relationships.

\section{Strengths and Limitations}

The current study has several important strengths. To start with, the design allowed for longitudinal analyses on the associations between parent-adolescent relationships and adolescent friendships with respect to perceived parental support, perceived conflict with parents, and perceived parental power in parent-adolescent relationships, thereby extending current knowledge based mainly on cross-sectional studies. The possible associations were examined in two age groups from early to middle adolescence and from middle to late adolescence, thanks to the availability of a total age range from 12 to 16 and from 16 to 20 years. In this way, our study makes a relevant contribution to the current knowledge on adolescent relationships over time.

The current study also has several limitations. Despite the longitudinal design, this study was nevertheless limited in that two groups of participants were assessed over five measurement waves, instead of one group that was assessed from early to late adolescence. In future research a longitudinal design that covers the entire age period of adolescence would be preferable.

Another limitation was that the data were based on selfreports of adolescents and therefore only describe adolescents' perceptions of relationships with parents and friends. This is specifically problematic considering that different informants often report different perceptions (Renk et al. 2008; Vierhaus and Lohaus 2008). On the other hand, it has been frequently found that adolescents more accurately report about their relationships than, for example, parents with respect to unpleasant aspects and that adolescents' perceptions regarding conflict are more likely to match reports from independent observers (Collins and Laursen 2004). Furthermore, relationship quality is for a large part in the "eye of the beholder" (Branje et al. 2002) and adolescents' perceptions of their relationships might influence interactions and adolescent developmental outcomes. Nevertheless, using observations or multiinformant questionnaires could give more information on development in these relationships.

Furthermore, friendship stability was not taken into account in this study, so the results are based on both stable and non-stable friendships. Stable friendships have been found to be more satisfying and with higher levels of commitment and relationship quality than non-stable friendships (Branje et al. 2007; Kiesner et al. 2005; Newcomb et al. 1999). Possibly, these long lasting friendships could have a stronger influence on parent-adolescent relationships than short-lived friendships. Also, parentchild relationships might have a larger influence on longer lasting friendships compared to shorter friendships. Future research could distinguish between stable and non-stable friends in order to see whether adolescents with stable and non-stable friendships differ regarding linkages between parent-child relationships and friendships.

Lastly, we did not include adolescents' gender in this study, since we had no reason to expect that adolescent boys and girls would differ on the relationship dynamics being considered in this research. However, it might be possible that for girls influences between the different relationships are stronger, due to the higher intensity of these relationships. Including gender in future research could indicate whether or not this is the case.

\section{Conclusions}

All in all, our results showed that relationship characteristics in adolescent relationships with parents and friends are mainly bidirectionally associated over time with a stronger influence from parent-adolescent relationships to friendships than vice versa in early to middle adolescence and an equal mutual influence in middle to late adolescence. Several points are relevant to highlight. (1) Perceptions of adolescents about their relationships with parents and friends were positively associated, indicating overlap between how interactions are experienced in different social worlds. (2) The significant influence from relationships with parents to relationships with friends confirmed a parent effect model, suggesting that perceptions of relationships with parents generalize to friendships. (3) In the same manner, the significant influence from relationships with friends to relationships with parents validated a friend effect model, suggesting a generalization from relationship skills and principles of adolescent friendships to relationships with parents. (4) The influence of parents decreased, confirming the idea that parents become less important in the lives of adolescents. (5) The influence of friends increased, confirming the idea that friends become more important in the lives of adolescents. (6) The mutual influence between parent-adolescent relationships and adolescent friendships was of equal strength in middle to late adolescence, indicating that both social worlds become equally important and overlapping towards late adolescence. Overall, the findings of this study show that parent-adolescent relationships and adolescent friendships are mutually linked. Even though the general 
influence from parents to friends is stronger than vice versa in early to middle adolescence, the mutual influence between adolescent relationships with parents and friends becomes equally strong from middle adolescence onwards.

Open Access This article is distributed under the terms of the Creative Commons Attribution Noncommercial License which permits any noncommercial use, distribution, and reproduction in any medium, provided the original author(s) and source are credited.

\section{References}

Bandura, A. (1977). Social learning theory. Englewood Cliffs, NJ: Prentice-Hall.

Bell, L. G., Cornwell, C. S., \& Bell, D. C. (1988). Peer relationships of adolescent daughters: A reflection of family relationship patterns. Family Relations, 37, 171-174. doi:10.2307/584316.

Benson, M. J., McWey, L. M., \& Ross, J. J. (2006). Parental attachment and peer relations in adolescence: A meta-analysis. Research in Human Development, 3, 33-43. doi:10.1207/s1542 7617rhd0301_4.

Berndt, T. J. (2002). Friendship quality and social development. Current Directions in Psychological Science, 11, 7-10. doi: 10.1111/1467-8721.00157.

Blos, P. (1967). The second individuation process of adolescence. The Psychoanalytic Study of the Child, 22, 162-186.

Blos, P. (1979). The adolescent passage: Developmental issues. New York: International Universities Press.

Bowlby, J. (1969). Attachment and loss: Attachment (Vol. 1). New York: Basic Books.

Branje, S. J. T., Frijns, T., Finkenauer, C., Engels, R., \& Meeus, W. (2007). You are my best friend: Commitment and stability in adolescents' same-sex friendships. Personal Relationships, 14, 587-603. doi:10.1111/j.1475-6811.2007.00173.x.

Branje, S. J. T., van Aken, M. A. G., \& van Lieshout, C. F. M. (2002). Relational support in families with adolescents. Journal of Family Psychology, 16, 351-362. doi:10.1037/0893-3200.16.3.351.

Brown, B. B. (2004). Adolescents' relationships with peers. In R. M. Lerner \& L. Steinberg (Eds.), Handbook of adolescent psychology (pp. 363-394). Hoboken, NJ: Wiley.

Bukowski, W. M., Hoza, B., \& Boivin, M. (1994). Measuring friendship quality during pre- and early adolescence: The development and psycho-metric properties of the friendship qualities scale. Journal of Social and Personal Relationships, 11, 471-484. doi:10.1177/ 0265407594113011

Burks, V. S., \& Parke, R. D. (1996). Parent and child representations of social relationships: Linkages between families and peers. Merrill-Palmer Quarterly, 42, 358-378.

Collins, W. A., \& Laursen, B. (2004). Changing relationships, changing youth: Interpersonal contexts of adolescent development. The Journal of Early Adolescence, 24, 55-62. doi:10.1177/02724 31603260882 .

Collins, W. A., Laursen, B., Mortensen, N., Luebker, C., \& Ferreira, M. (1997). Conflict processes and transitions in parent and peer relationships: Implications for autonomy and regulation. Journal of Adolescent Research, 12, 178-198. doi:10.1177/0743554897 122003.

Collins, W. A., \& Repinski, D. J. (1994). Relationships during adolescence: Continuity and change in interpersonal perspective. In R. Montemayor (Ed.), Personal relationships during adolescence (pp. 7-36). Thousand Oaks: Sage.

Cui, M., Conger, R., Bryant, C., \& Elder, G. (2002). Parental behavior and the quality of adolescent friendships: A social contextual perspective. Journal of Marriage and the Family, 64, 676-689. doi:10.1111/j.1741-3737.2002.00676.x.

De Goede, I. H. A., Branje, S. J. T., \& Meeus, W. H. J. (2009). Developmental changes in adolescents' perceptions of relationships with their parents. Journal of Youth and Adolescence, 38, 75-88. doi:10.1007/s10964-008-9286-7.

Edens, J. F., Cavell, T. A., \& Hughes, J. N. (1999). The self-systems of aggressive children: A cluster-analytic investigation. Journal of Child Psychology and Psychiatry, and Allied Disciplines, 40, 441-453. doi:10.1111/1469-7610.00461.

Erel, O., \& Burman, B. (1995). Interrelatedness of marital relations and parent-child relations: A meta-analytic review. Psychological Bulletin, 118, 108-132. doi:10.1037/0033-2909.118.1.108.

Furman, W. (1996). The measurement of friendship perceptions: Conceptual and methodological issues. In W. M. Bukowski, A. F. Newcomb, \& W. W. Hartup (Eds.), The company they keep: Friendship in childhood and adolescence (pp. 41-65). New York: Cambridge University Press.

Furman, W., \& Buhrmester, D. (1985). Children's perceptions of the personal relationships in their social networks. Developmental Psychology, 21, 1016-1024. doi:10.1037/0012-1649.21.6.1016.

Furman, W., \& Buhrmester, D. (1992). Age and sex differences in perceptions of networks of personal relationships. Child Development, 63, 103-115. doi:10.2307/1130905.

Furman, W., Simon, V. A., Schaffer, L., \& Bouchey, H. A. (2002). Adolescents' working models and styles for relationships with parents, friends, and romantic partners. Child Development, 73, 241-255. doi:10.1111/1467-8624.00403.

Graziano, W. G. (1984). A developmental approach to social exchange processes. In J. C. Masters \& K. Yarkin-Levin (Eds.), Boundary areas in social and developmental psychology. Orlando, FL: Academic Press.

Grotevant, H. D., \& Cooper, C. R. (1986). Individuation in family relationships: A perspective on individual differences in the development of identity and role-taking skill in adolescence. Human Development, 29, 82-100.

Hartup, W. (1989). Social relationships and their developmental significance. The American Psychologist, 44, 120-126. doi:10.1037/ 0003-066X.44.2.120.

Helsen, M., Vollebergh, W., \& Meeus, W. (2000). Social support from parents and friends and emotional problems in adolescence. Journal of Youth and Adolescence, 29, 319-335. doi:10.1023/A:100514 7708827.

Kiesner, J., Nicotra, E., \& Notari, G. (2005). Target specificity of subjective relationship measures: Understanding the determination of item variance. Social Development, 14, 109-135. doi: 10.1111/j.1467-9507.2005.00293.x.

Kline, R. B. (2005). Principles and practice of structural equation modeling. New York: The Guilford Press.

Larson, R. W., Richards, M. H., Moneta, G., Holmbeck, G., \& Duckett, E. (1996). Changes in adolescents' daily interactions with their families from ages 10 to 18: Disengagement and transformation. Developmental Psychology, 32, 744-754. doi:10.1037/00121649.32.4.744.

Laursen, B. (1996). Closeness and conflict in adolescent peer relationships: Interdependence with friends and romantic partners. In W. M. Bukowski, A. F. Newcomb, \& W. W. Hartup (Eds.), The company they keep: Friendship in childhood and adolescence (pp. 186-210). New York: Cambridge University Press.

Laursen, B., \& Bukowski, W. M. (1997). A developmental guide to the organization of close relationships. International Journal of Behavioral Development, 21, 747-770. doi:10.1080/0165025973 84596.

Laursen, B., \& Collins, W. A. (1994). Interpersonal conflict during adolescence. Psychological Bulletin, 115, 197-209. doi:10.1037/ 0033-2909.115.2.197. 
Laursen, B., Wilder, D., Noack, P., \& Williams, V. (2000). Adolescent perceptions of reciprocity, authority and closeness in relationships with mothers, fathers and friends. International Journal of Behavioral Development, 24, 464-471. doi:10.1080/ 016502500750038017.

McDowell, D. J., Parke, R. D., \& Spitzer, S. (2002). Parent and child cognitive representations of social situations and children's social competence. Social Development, 4, 486-496.

McGue, M., Elkins, I., Walden, B., \& Iacono, W. G. (2005). Perceptions of the parent-adolescent relationship: A longitudinal investigation. Developmental Psychology, 41, 971-984. doi:10.1037/ 0012-1649.41.6.971.

Meeus, W. H. J., Akse, J., Branje, S. J. T., Ter Bogt, T., Delsing, M., Van Doorn, M. D., et al. (2004). [Codebook of the research project conflict and management of relationships (CONAMORE)]. Unpublished manuscript, Utrecht University, The Netherlands.

Newcomb, A. F., Bukowski, W. M., \& Bagwell, C. L. (1999). Knowing the sounds: Friendship as a developmental context. In W. A. Collins \& B. Laursen (Eds.), The Minnesota symposia on child psychology. Relationships as developmental contexts (Vol. 30, pp. 63-84). Mahwah, NJ: Erlbaum.

Parke, R. D., \& Buriel, R. (2006). Socialization in the family: Ethnic and ecological perspectives. In N. Eisenberg (Ed.), Handbook of child psychology: Social, emotional, and personality development (6th ed., Vol. 3, pp. 429-504). New York: Wiley.

Parke, R. D., Burks, V. M., Carson, J. L., Neville, B., \& Boyum, L. A. (1994). Family-peer relationships: A tripartite model. In R. D. Parke \& S. G. Kellam (Eds.), Exploring family relationships with other social contexts (pp. 115-145). Hillsdale, NJ: Lawrence Erlbaum.

Parker, J. G., \& Asher, S. R. (1993). Friendship and friendship quality in middle childhood: Links with peer group acceptance and feelings of loneliness and social dissatisfaction. Developmental Psychology, 29, 611-621. doi:10.1037/0012-1649.29.4.611.

Renk, K., Donelly, R., Klein, J., Oliveros, A., \& Baksh, E. (2008). Cross-informant ratings of the emotional and behavioral functioning of college students. Journal of Youth and Adolescence, 37, 193-210. doi:10.1007/s10964-006-9149-z.

Rubin, K. H., Bukowski, W., \& Parker, J. G. (2006). Peer interactions, relationships, and groups. In W. Damon, R. M. Lerner, \& N. Eisenberg (Eds.), Handbook of child psychology: Social, emotional, and personality development (Vol. 3). New York: Wiley.

Russell, A., Pettit, G. S., \& Mize, J. (1998). Horizontal qualities in parent-child relationships: Parallels with and possible consequences for children's peer relationships. Developmental Review, 18, 313-352. doi:10.1006/drev.1997.0466.

Satorra, A., \& Bentler, P. M. (1994). Corrections to test statistics and standard errors in covariance structure analysis. In A. von Eye \& C. C. Clogg (Eds.), Latent variables analysis: Applications for developmental research (pp. 399-419). Thousand Oaks, CA: Sage.

Satorra, A., \& Bentler, P. M. (2001). A scaled difference chi-square test statistic for moment structure analysis. Psychometrika, 66, 507-514. doi:10.1007/BF02296192.

Schneider, B., Atkinson, L., \& Tardif, C. (2001). Child-parent attachment and children's peer relations: A quantitative review. Developmental Psychology, 37, 86-100. doi:10.1037/0012-1649. 37.1.86.

Selman, R. L. (1980). The growth of interpersonal understanding. New York: Academic Press.
Selman, R. (1981). The child as friendship philosopher. In S. R. Asher \& J. M. Gottman (Eds.), The development of children's friendships. Cambridge: Cambridge University Press.

Shulman, S., Laursen, B., Kalman, Z., \& Karpovsky, S. (1997). Adolescent intimacy revisited. Journal of Youth and Adolescence, 26, 597-617. doi:10.1023/A:1024586006966.

Stice, E., Ragan, J., \& Randall, P. (2004). Prospective relations between social support and depression: Differential direction of effects for parent and peer support? Journal of Abnormal Psychology, 113, 155-159. doi:10.1037/0021-843X.113.1.155.

Sullivan, H. S. (1953). The interpersonal theory of psychiatry. New York: W.W. Norton.

Vierhaus, M., \& Lohaus, A. (2008). Children and parents as informants of emotional and behavioural problems predicting female and male adolescent risk behaviour: A longitudinal cross-informant study. Journal of Youth and Adolescence, 37, 211-224. doi: 10.1007/s10964-007-9193-3.

Wilkinson, R. B. (2006). Age and sex differences in the influence of attachment relationships on adolescent psychological health. The Australian Educational and Developmental Psychologist, 23, 87-109.

Young, J. F., Berenson, K., Cohen, P., \& Garcia, J. (2005). The role of parent and peer support in predicting adolescent depression: A longitudinal community study. Journal of Research on Adolescence, 15, 407-423. doi:10.1111/j.1532-7795.2005.00105.x.

Youniss, J., \& Smollar, J. (1985). Adolescent relations with mothers, fathers, and friends. Chicago: The University of Chicago Press.

Zimmer-Gembeck, M. J., \& Collins, W. A. (2003). Autonomy development during adolescence. In G. R. Adams \& M. Berzonsky (Eds.), Blackwell handbook of adolescence (pp. 175-204). Oxford: Blackwell Publishers.

Zimmermann, P. (2004). Attachment representations and characteristics of friendship relations during adolescence. Journal of Experimental Child Psychology, 88, 83-101. doi:10.1016/j.jecp. 2004.02.002.

\section{Author Biographies}

Irene De Goede is a $\mathrm{PhD}$ candidate at Utrecht University. She received her master's degree in 2003 from Utrecht University. Her research interests include development of adolescent relationships.

Susan Branje is an Associate Professor at Utrecht University. She received her $\mathrm{PhD}$ in 2003 from the Radboud University Nijmegen. Her research interests include adolescent development and the influence of parents and friends.

Marc Delsing is researcher at Praktikon. He received his PhD in 2004 from the Radboud University Nijmegen. His research interests include family relationships, youth culture, music preference, societal participation, personality, and problem behavior in adolescence.

Wim Meeus is Full Professor of Adolescent Development at Utrecht University. He received his PhD in 1984 from Utrecht University. His major research interests include personality, identity, and relationships in adolescence. 